\title{
THE SALT DISCHARGE OF AN ISOLATED MYELINATED NERVE FIBRE OF TOADS
}

\author{
KONOSUKE NAKAMURA \\ Department of Physiology, School of Medicine, \\ Keio University
}

(Received on January 7,1959 )

When an excised sartorious or other skeletal muscle of frogs is bathed wholly or partly in an isotonic sodium chloride solution, it may exhibit spontaneous movements, rather rhythmic contractions and continue for a long time. This phenomenon was first called attention to by Heering in 1879, and Biederman in the following year. These contractions were more adequately described by Ringer, in 1886, since then this phenomenon has been dealt with by several observers especially by Mines(7). Adrian touched the phenomenon with regard to the action

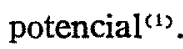

Hayashi, studying this phenomenon since 1944, named it the "salt contraction" and has proposed a theory of the "Excitin-Inhibitin hypothesis" of muscular contraction $^{(5)}$.

In nerves, are there any corresponding phenomena to the salt contraction of muscle? If a mass of sodium chloride crystal was applied upon a nerve ${ }^{(8)}$ or hypertonic sodium chloride solution bathed the nerve ${ }^{(9)}$, there appeared repetitive contractions of the attached muscle. But when a part of the sciatic nerve of a frog was immersed in normal saline solution $(0.7 \% \mathrm{NaCl}$ solution), there occurred no contraction in the attached muscle. If the perineurium of the nerve is taken off $10.0-20.0 \mathrm{~mm}$ long and the denuded part is immersed in saline solution, the attached muscle begins to contract with a latent period of several seconds, and it continues repetitively ${ }^{(s)}$. Bronk and his associates considered that the depletion of $\mathrm{Ca}$ ion made some structure of nerve unstable, as the consequence of this loss of stability self excitation would $\operatorname{occur}^{(3)}$. On the contrary, Hayashi concluded from his enormous work that this phenomenon should be produced through the same mechanism as the salt contraction, and named it the "salt discharge of nerve" ${ }^{(5)}$.

Hayashi pointed out, that the isolated single muscle fibre never produced the salt contraction, whereas a bundle of several fibres as well as the whole muscle showed the salt contraction, and said, that the presence of a certain number of 
muscle fibres in a mass seemed to be a necessary condition for the occurrence of the salt contraction ${ }^{(2)(6)}$. How is it in nerve fibre? In the present work the salt discharge of an isolated single myelinated nerve fibre from the toad was studied.

\section{METHOD}

The excised sciatic nerve-sartorius muscle preparations of the Japanese toads ${ }^{(10)}$ were used. The materials were denuded at the sciatic nerve trunk and were isolated to a single myelinated nerve fibre at the near point to the attached muscle by needles ${ }^{(11)}$ under a binoculor microscope, and mounted on a bridge insulator with two separated pieces of glass plate each of which had a pool of Ringer solution on it. The air gap between the glass-plates served to isolate these pools from one another (Fig. 1). From then Ringer solution in Pool 1 was changed to normal saline solution. The details will be described in each experiment in the following section.

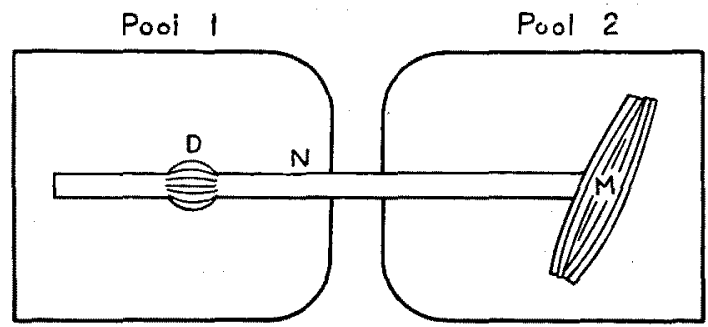

Fig. 1. D: denuded part of nerve. $\mathrm{N}$ : non-denuded part of nerve. M: sartorius muscle. Air gap is $10.0 \mathrm{~mm}$ length. Ringer solution in Pool 1 is changed to normal saline solution.

\section{RESULT}

1. The salt discharge of the denuded part of the nerve

The denuded nerve-muscle preparation was mounted on the bridge insulator, so that the denuded part of the nerve would be bathed in the saline solution in Pool 1, and the muscle in Ringer solution in Pool 2 and the air gap was bridged by the non-denuded part of the nerve trunk as shown in Fig. 1. In most cases, after a certain latency, the attached muscle began to contract. After a time, the saline solution of Pool 1 was changed to Ringer solution. The salt discharge ceased at once. Five minutes later, the Ringer solution was changed again to the normal saline solution, and the attached muscle began to contract again with the same or a rather shorter latency, and it continued for a long time (Table 1). In some cases, after thirty minutes observation, the distal point of the denuded part of the nerve was cut off and the contraction of the attached muscle ceased at 
once. This should show, that the repetitive contractions of the attached muscle were not the movements caused by spontaneous activities origined in the muscle itself, but the real salt discharge of the nerve.

Table 1

The Salt Discharge of the Denuded Part of the Nerve

\begin{tabular}{rccccc}
\hline No. & $\begin{array}{c}\text { Room } \\
\text { temperature } \\
{ }^{\circ} \mathrm{C}\end{array}$ & $\begin{array}{c}\text { Saline } \\
\text { solution } \\
\mathrm{ml}\end{array}$ & $\begin{array}{c}\text { Latency } \\
\min \end{array}$ & $\begin{array}{c}\text { Duration } \\
\text { min }\end{array}$ & $\begin{array}{c}\text { Salt } \\
\text { discharge }\end{array}$ \\
\hline 1 & 22 & 20 & 6 & $30+\alpha$ & + \\
2 & 23 & 20 & 11 & $30+\alpha$ & + \\
3 & 23 & 20 & 7 & $30+\alpha$ & + \\
4 & 24 & 5 & 0.5 & $30+\alpha$ & + \\
5 & 18 & 20 & - & - & - \\
6 & 18 & 20 & 2 & $30+\alpha$ & + \\
7 & 18 & 20 & - & - & - \\
8 & 19 & 20 & 4 & $30+\alpha$ & + \\
9 & 20 & 20 & 2 & $30+\alpha$ & + \\
10 & 24 & 10 & 1 & $30+\alpha$ & + \\
11 & 24 & 10 & 2 & $30+\alpha$ & + \\
\hline
\end{tabular}

2. The salt discharge of an isolated single myelinated nerve fibre

The endoneurium of the sartorius branch of the sciatic nerve of a toad was depleted and a single nerve fibre was isolated. Then the material was mounted on the bridge insulator as shown in Fig. 1, that is, the single nerve fibre part was placed in normal saline solution in Pool 1, the muscle in Ringer solution in Pool 2. Among the above 13 experiments, only one produced the salt discharge.

Table 2

The Salt discharge of a Nerve Reduced to Several Nerve Fibres

\begin{tabular}{cccccc}
\hline No. & $\begin{array}{c}\text { Room } \\
\text { temperature } \\
{ }^{\circ} \mathrm{C}\end{array}$ & $\begin{array}{c}\text { Saline } \\
\text { solution } \\
\mathrm{ml}\end{array}$ & $\begin{array}{c}\text { Latency } \\
\text { min }\end{array}$ & $\begin{array}{c}\text { Duration } \\
\text { min }\end{array}$ & $\begin{array}{c}\text { Salt } \\
\text { discharge }\end{array}$ \\
\hline 1 & 14 & 30 & - & - & - \\
2 & 14 & 30 & - & - & - \\
3 & 14 & 30 & - & - & - \\
4 & 15 & 30 & 4 & $30+\alpha$ & + \\
5 & 14 & 30 & - & - & - \\
6 & 15 & 30 & 2 & $30+\alpha$ & + \\
7 & 15 & 30 & 3 & $30+\alpha$ & + \\
8 & 15 & 30 & - & - & - \\
9 & 15 & 20 & 5 & $30+\alpha$ & + \\
\hline
\end{tabular}


3. The salt discharge of a nerve reduced to several nerve fibres

Only one example produced the salt discharge in the single nerve fibre-muscle preparation. A bundle of several muscle fibres produced the salt contraction as well as in one whole muscle, In this experiment, a nerve was severed from the outside fibres and reduced to several fibres at which a part of the nerve was immersed in normal saline solution, and it was confirmed that the salt discharge was produced in such a preparation as in the denuded part of the nerve (Table 2).

4. The salt discharge of a denuded central site of a single nerve fibre

When a denuded part of a nerve produced the salt discharge on the bridge insulator, a single nerve fibre was isolated at the distal part under a binoculor microscope. Then the material was mounted on the bridge insulator again as shown in Fig. 2. The denuded part of the nerve was immersed in normal saline solution in Pool 1 and the part of single nerve fibre as well as the attached muscle

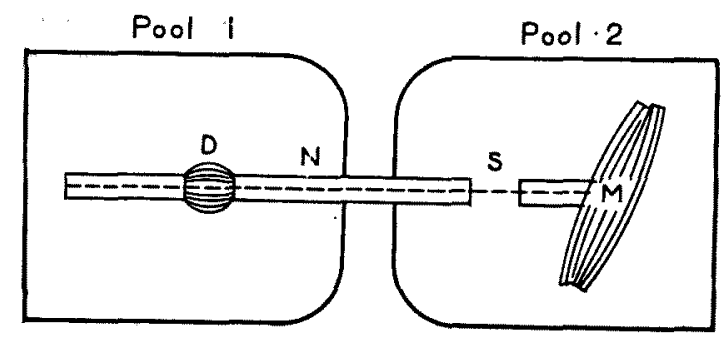

Fig. 2 D: denuded part of nerve. $N$ : non-denuded part of nerve. $\mathrm{S}$ : single nerve fibre part. $\mathrm{M}$ : sartorius muscle. When the denuded central site of the single nerve fibre produces the salt discharge, the innervated muscle fibres will contract. But the salt discharge of the other fibres in a denuded part of the nerve cannot excite the muscle.

Table 3

The Salt Discharge of the Denuded Central Site of a Single Nerve Fibre

\begin{tabular}{ccccccc}
\hline \hline No. & $\begin{array}{c}\text { Room } \\
\text { temperat. } \\
{ }^{\circ} \mathrm{C}\end{array}$ & $\begin{array}{c}\text { Latency of } \\
\text { denuded } \\
\text { nerve } \\
\text { min }\end{array}$ & $\begin{array}{c}\text { Saline } \\
\text { solution } \\
\mathrm{ml}\end{array}$ & $\begin{array}{c}\text { Latency of } \\
\text { single } \\
\text { nerve fibre } \\
\text { min }\end{array}$ & $\begin{array}{c}\text { Duration } \\
\text { min }\end{array}$ & $\begin{array}{c}\text { salt } \\
\text { discharge }\end{array}$ \\
\hline 1 & 26 & 2 & 20 & 1 & $30+\alpha$ & + \\
2 & 23 & 7 & 20 & 7 & $30+\alpha$ & + \\
3 & 22 & 6 & 20 & 4 & $30+\alpha$ & + \\
4 & 19 & 4 & 20 & 5 & $30+\alpha$ & + \\
5 & 19 & 2 & 20 & 3 & $30+\alpha$ & + \\
6 & 20 & 2 & 20 & 3 & $30+\alpha$ & + \\
7 & 20 & 3 & 20 & 3 & $30+\alpha$ & + \\
\hline
\end{tabular}


was placed in Ringer solutidn in Pool 2. This denuded central site of the isolated single nerve fibre produced the salt discharge in all examples as shown in Table 3.

\section{DISCUSSION}

Salt discharge of a nerve never appeared in an excised nerve of a toad. But when the perineurium of it was deprived, the discharge occurred and continued for several hours. It is presumed, that the perineurium is a barrier to the diffusion of ions into the intrastitial cell fluid, as already pointed by Feng and others ${ }^{(4)}$.

The evidence, that the above assumption was correct, was due to the experiment that every nerve was deprived of its perineurium at which site it was bathed in normal saline solution, and the distal part was severed to isolate a single motor fibre, which produced the salt discharge. On the contrary it was a surprise that the isolated single nerve fibre had difficulty to produce the salt discharge. For it is unreasonable, that whereas every motor fibre would produce the salt discharge, the isolated one did not.

Hayashi pointed also out that the salt contraction of a muscle never appeared in isolated single muscle fibres and presumed, that it was impossible to isolate a single muscle fibre without injury, for through the isolating process one must separate the neighbouring muscle fibres by force. If the salt contraction of a muscle needs the fibre to stay alsolutely intact, the fibres must be in a mass, which contents at least one intact fibre.

The process of isolating single myelinated nerve fibre, especially from the sartorius branch of the toads sciatic nerve is easier than isolating single muscle fibre and it has normal conduction, but to produce the salt discharge, a more natural state would be needed. It is natural to think that the nerve fibres in the denuded part of the nerve are nearer to the normal state than the isolated single nerve fibres, for the perineurium is only a small part of the connective tissue sheath of nerve. The major part of the sheath is the endoneurium. The denuding method will not make change so much in properties of nerve fibre. The fact that the salt discharge of an isolated single myelinated nerve fibre is seldom, rather shows that the salt discharge does not appear in an injured fibre. From these considerations the theory that the salt discharge is generated from the injury potential is rather absurd.

\section{SUMMARY}

1. The salt discharge of isolated single myelinated nerve fibres of the sciatic nerve-sartorius muscle prepations of the Japanese toads has been studied.

2. The denuded part of the nerve produced active salt discharge. 
3. It was difficult to make the isolated single myelinated nerve fibre produce salt discharge.

4. The nerve reduced to several nerve fibres produced the salt discharge as well as the denuded part of the nerve.

5. The denuded central site of the single nerve fibre exhibited the salt discharge in all examples, and it was confirmed, that most nerve fibres in denuded part of the nerve produced salt discharge.

6. The reason why isolated single muscle fibres or single nerve fibres never produce salt contraction or salt discharge, was discussed. It was concluded that the absolutely intact state of a muscle or nerve fibre is necessary to produce salt contractions of muscle or salt discharge of nerve.

\section{ACKNOWLEDGEMENT}

I wish to thank Prof. T. Hayashi for taking the trouble to read this manuscript and his many helpful suggestions.

\section{REFERENCES}

1. Adrian, E. D. \& Gelfans. : Rhythmic activity in skeletal muscle fibers. J. Physiol., 78: 271-287, 1933.

2. Ashkenaz, E. W.: Anomalous behavior of isolated muscle fibers toward certain chemical stimuli. Proc. Soc. Exp. Biol. \& Med., 38: 719-720, 1938.

3. Brink, F., Bronk D. W. \& Larrabee M. G.: Chemical excitation of nerve. Ann. N. Y. Acad. Sci., $47:$ 457-485, 1946.

4. Feng, T. P. \& Liu T. M. : The connective tissue sheath of nerve as effective diffusion barrier. J. Cell. Comp. Physiol., 34:1-16, 1949.

5. Hayashi, T.: Chemical physiology of excitation in muscle and nerve. Nakayama-shoten, Ltd., Tokyo, Japan 1956.

6. Heilbrum, L. V.: An outline of general physiology. W. B. Saunders Company, Phyladelphia, London. 1952.

7. Meines, G. R.: On the spontaneous movements of amphibian skeletal muscle in saline solutions, with observations on the influence of potassium and calcium chlorides on muscular excitability. J. Physiol. $23: 408-444,1908$.

8. Müller, P.: Ueber lokale Potentialwellen und rhythmische Entladungen an parabiotischen Nervenstellen des Frosches. Pflüg. Arch. Ges. Physiol., 257/2: 112-120, 1953.

9. Sato, M.: Observations on the repetitive responses of nerve fibers. Part 1. Repetition of nerve fibers treated with hypertonic $\mathrm{NaCl}$ solutions. Jap. J. Physiol., 1:125-132, 1951.

10. Tasaki, I.: The strength-duration relation of normal polarized and narcotized nerve fiber. Am. J. Physiol., 125: 367-379, 1939.

11. Tasaki, I.: Nervous transmission. Charles C Thomas Publisher, Springfield, Illinois, U. S. A. 141-145, 1953. 